Review Article

\title{
Recurrent Painful Ophthalmoplegic Neuropathy and Oculomotor Nerve Schwannoma: A Pediatric Case Report with Long-Term MRI Follow-Up and Literature Review
}

\author{
Maria Giuseppina Petruzzelli $(\mathbb{D}$, Mariella Margari, Flora Furente, \\ Maria Carmela Costanza, Anna Rosi Legrottaglie, Franca Dicuonzo, and Lucia Margari
}

Department of Basic Medical Sciences, Neurosciences and Sense Organs Department, University of Bari "Aldo Moro", Bari, Italy

Correspondence should be addressed to Maria Giuseppina Petruzzelli; maria.petruzzelli@uniba.it

Received 5 July 2019; Accepted 9 September 2019; Published 25 September 2019

Academic Editor: Parisa Gazerani

Copyright (c) 2019 Maria Giuseppina Petruzzelli et al. This is an open access article distributed under the Creative Commons Attribution License, which permits unrestricted use, distribution, and reproduction in any medium, provided the original work is properly cited.

\begin{abstract}
Background. Recurrent painful ophthalmoplegic neuropathy (RPON), previously known as ophthalmoplegic migraine (OM), is an uncommon disorder with repeated episodes of ocular cranial nerve neuropathy associated with ipsilateral headache. The age of presentation is most often during childhood or adolescence. MRI has a central role in the assessment of the RPON, especially to distinguish orbital, parasellar, or posterior fossa lesions that mimic symptoms of RPON. Actually, oculomotor nerve tumors may be masquerade as RPON so that MRI follow-ups are required to detect the possibility of tumor etiology. Case presentation. We report a 16-year-old boy with a 7-year follow-up and multiple brain MRI data, previously diagnosed as OM. The last brain MRI, performed during an acute phase of oculomotor paresis with ipsilateral headache, showed a nodular lesion described as schwannoma of III cranial nerve. Then, we reviewed the literature on OM and RPON in pediatric age with a focus on brain MRI findings. Conclusions. This review highlights the important role of serial brain MRIs in the long-term follow-up of RPON, especially in the cases with childhood onset, in order to not delay the diagnosis of a possible oculomotor nerve schwannoma.
\end{abstract}

\section{Introduction}

In the $3^{\text {rd }}$ edition of International Classification of Headache Disorders (ICHD) (2018) has been introduced a chapter named "painful lesions of the cranial nerves and other facial pains" after a consensus between the International Headache Society (IHS) and the International Association for the Study of Pain (IASP) [1]. The IASP defines neuropathic pain (NP) as "pain arising as a direct consequence of a lesion or disease affecting the somatosensory system" [2]. There is increasing awareness about NP in pediatric chronic pain because there are fewer information available regarding the prevalence of NP in the pediatric population than adults [3], and the affected children experience significant physical, psychological, and social sequelae that affect not only themselves but also family and friends [4]. The chapter "painful lesions of the cranial nerves and other facial pains" includes the recurrent painful ophthalmoplegic neuropathy (RPON), a condition characterized by repeated attacks of paresis of one or more ocular cranial nerves (commonly the III nerve), with ipsilateral headache [1]. This disorder is extremely rare and can occur at any age, but the highest prevalence is in children under the age of 12 years, with the median age at onset about 8 years [5]. The diagnostical definition of RPON changed throughout the history of headache classifications. The $1^{\text {st }}$ edition (1987) of the ICHD had considered this condition as a migraine variant [6], but in the ICHD-II (2004), the disorder, called "ophthalmoplegic migraine" (with the quotes around "migraine" included), was classified in the group of cranial neuralgias and central causes of facial pain [7]. However, the International Headache Society again revised the classification in 2013, renaming the disorder "RPON" [8]. Brain magnetic resonance imaging (MRI) is essential in the assessment of 
RPON to exclude orbital, parasellar, or posterior fossa lesions. Gadolinium enhancement of the affected nerve or nerve thickening can be evident using MRI during an acute episode of RPON, whereas negative findings are common during the period of full recovery $[1,9,10]$. Moreover, few MRI studies show the presence of a schwannoma in some patients with RPON disease. Isolated schwannomas are extremely rare. They are benign peripheral nerve sheath tumors, with slowlygrowing, accounting for $6 \%$ to $8 \%$ of all intracranial tumors $[11,12]$. They usually arise from the Schwann cell layer of the vestibular branch of the VIII nerve; otherwise oculomotor nerve schwannomas without neurofibromatosis are very rare, and only few cases with pediatric onset have been described in literature [11-13]. In the contest of this ongoing debate [14] about the classification of RPON, we presented a pediatric case report with a 7-year follow-up and multiple brain MRI data, previously diagnosed as OM. The last brain MRI during an acute phase of oculomotor paresis with ipsilateral headache showed a nodular lesion described as schwannoma of III cranial nerve. Then, we reviewed the literature on OM and RPON with a focus on brain MRI findings.

\section{Methods of Review}

An electronic literature search was conducted for all articles published up to December 2018, with a range of databases searched including PubMed, Scopus, and Web of Science. The following combinations of keywords were searched: "opthalmoplegic migraine AND magnetic resonance imaging" and "recurrent painful ophthalmoplegic neuropathy AND magnetic resonance imaging." The initial search returned 227 records; we considered 117 publications after screening to remove duplication of papers from different sources of research. Research articles, case reports, and reviews describing patients under the age of 18 years have been included. As inclusion criteria papers needed to provide enough information to extract clinical features of headache and oculomotor involvement and a description of MRI findings, 28 publications for a total of 43 clinical cases were selected for inclusion in this review.

\section{Case Report}

We reported the case of a male patient, 16 years old, with a history of frontal headaches accompanied by photophobia, nausea, and vomiting since the age of 4 . He had his first episode of migraine associated with ocular pain and ptosis in the right eyelid, lasting 24 hours, in Jun 2010 at the age of 6 . Six months later (Jan 2011), he had a heavier and persistent episode of migraine associated with right ocular pain (partial responsiveness to administration of paracetamol), right ptosis, and diplopia, so he was admitted to the Child Neuropsychiatry Unit, Department of Basic Medical Sciences, Neuroscience and Sense Organs, University of Bari "Aldo Moro," Italy. Family history of migraine in both parents, multiple sclerosis in the father's family, and gastric neoplastic disease in the mother's family was referred. General physical examination was normal; neurologic examination showed paresis of the third and sixth cranial nerves. Laboratory investigation, including virological and organ-specific serum antibodies, and instrumental examination including awake/sleep electroencephalograph produced normal results. Brain and cervical-spine magnetic resonance imaging (MRI) enhanced after contrast administration and magnetic resonance angiography (MRA) produced normal findings. Diagnosis of "ophthalmoplegic migraine" was made according to ICHD 2, as discussed in a previous publication [10]. During the following years, about one time a month, the subject suffered from a moderate to severe intensity headache in the frontal and supraorbital region on the right side with a transient remission with paracetamol. Since his first hospitalization, he had 2 more episodes, in Jul 2013 and Jun 2016, of OM, with ocular pain ptosis in the right eyelid and diplopia. In both episodes brain MRI confirmed normal images. The diagnosis was revised as RPON according to the new diagnostic criteria of ICHD-3 beta (2013) [15]. At the age of 15 years (Sep 2018), the patient was again admitted to our Child Neuropsychiatry Unit manifesting moderate and persistent migraine, nausea, vomiting, phonophobia, and photophobia associated with right ocular pain, diplopia, and ptosis. Neurologic examination showed right eyelid ptosis, and ophthalmologic evaluation showed paresis of the III cranial nerve. Brain MRI with MRA revealed a 5-6 mm nodular enhancement mass, located within the fork of the right basilar artery near to perimesencephalic and interpeduncular cisterns, suggesting an oculomotor nerve schwannoma without any vascular malformation (Figures 1 and 2). The subject was treated with corticosteroid therapy because of the partial and transient responsiveness with paracetamol during acute episodes of right eye pain. He showed gradual and progressive improvement of headache symptoms in about one week.

\section{Discussion}

To our knowledge, this is the first case reported in the literature of an adolescent suffering from headache and ophthalmoplegia with a 7-year brain MRI follow-up, raising the question on the relationship between RPON and schwannoma. The evolutive changes in the presentation of symptoms and the different findings over time in brain MRI images observed in this patient repurpose some open issues on the classification and pathophysiological mechanisms of RPON. The patient had his first clinical manifestations of recurrent headaches at the age of 4 years agreeing to diagnostic criteria of migraine without aura. Since he was 7 years old, the patient started to have migraine episodes with the same clinical features but lasting more time and with partial responsiveness to administration of paracetamol with association of right ocular pain, ipsilateral ptosis, and diplopia. After two episodes with these features and with MRI that showed normal findings in the image scans without any appreciable enhancement or thickening of the nerve, he was diagnosed with "ophthalmoplegic migraine" according to ICHD-II [7]. Clinical and instrumental data at next followups were in agreement with the reclassification of RPON proposed in the ICHD-3 [1]. Brain MRI follow-ups of 2013 


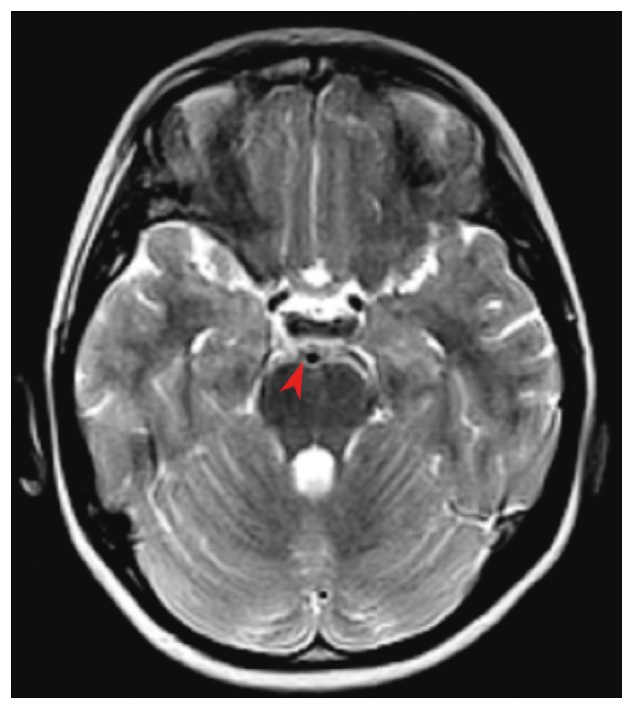

(a)

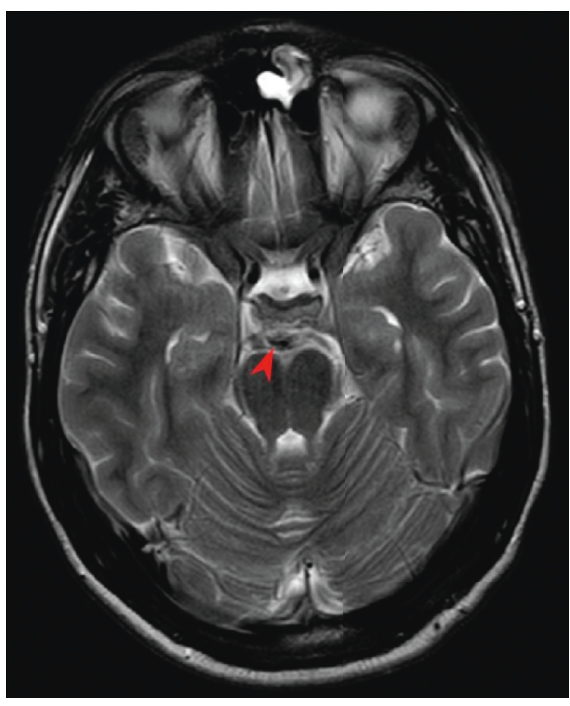

(b)

Figure 1: Axial T2-weighted MRI images comparison: (a) no focal or wide thickening of the oculomotor nerve during an acute attack of OM (Jan 2011); (b) 5-6 mm nodular mass suggesting an oculomotor nerve schwannoma (Oct 2018).

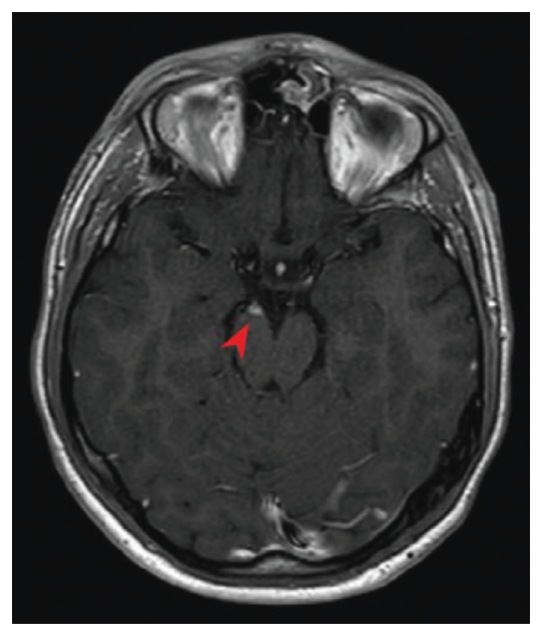

(a)

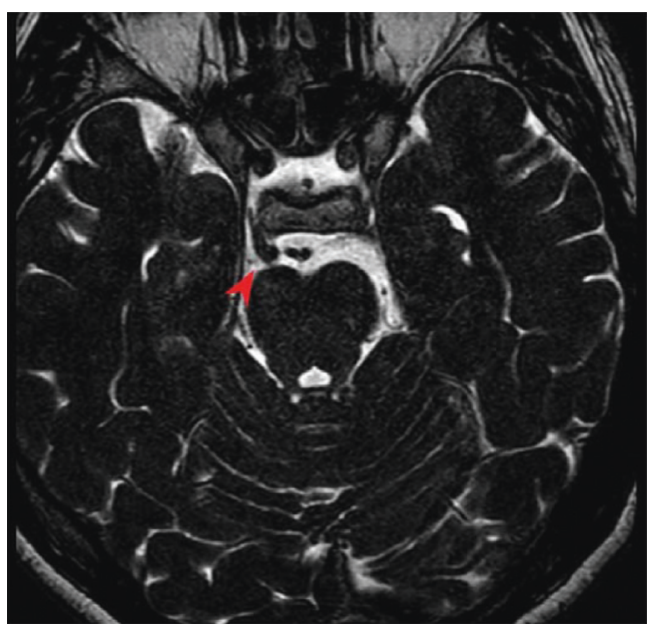

(b)

Figure 2: Axial T1-weighted (a) and axial T2-weighted (b) MRI images showing 5-6 mm nodular mass located within the fork of the right basilar artery near to perimesencephalic and interpeduncular cisterns (Oct 2018).

and 2016 both during an acute episode of headache with ophthalmoplegia confirmed normal findings in the image scans in absence of any brain MRI data supporting a secondary cause. At this regard, according to our review, patients diagnosed with OM/RPON have MRI exams that show thickening and enhancing of the oculomotor nerve $[9,16-24]$ or normal findings in image scans $[18,20,22,23,25-30]$. Nevertheless, the last brain MRI examination of our patient showed the presence of 5-6 mm nodular enhanced mass located within the fork of the right basilar artery near to perimesencephalic and interpeduncular cisterns, enhanced after contrast, which could be described as III cranial nerve schwannoma (Figures 1 and 2). This case highlights the important role of longitudinal follow-up of brain MRI in RPON and raises the question on the relationship between RPON and schwannoma. The exact pathophysiology of RPON is unknown, but the most accepted postulated mechanisms include microvascular ischemia, demyelization, and inflammation involving the oculomotor nerve [31]. Despite the reclassification as a neuropathy, a balanced debate on arguments pro and contra a migrainous background of RPON have been published. Friedman DI proposed to consider OM as a syndrome that may be "primary" as a variant of migraine with aura for cases with normal imaging and spontaneous resolution and "secondary" as a cranial neuropathy with focal nerve enhancement on neuroimaging [31]. The case we described is far from this classification hypothesis, considering that three different brain MRIs during an acute attack of OM showed normal findings inducing to consider the clinical 


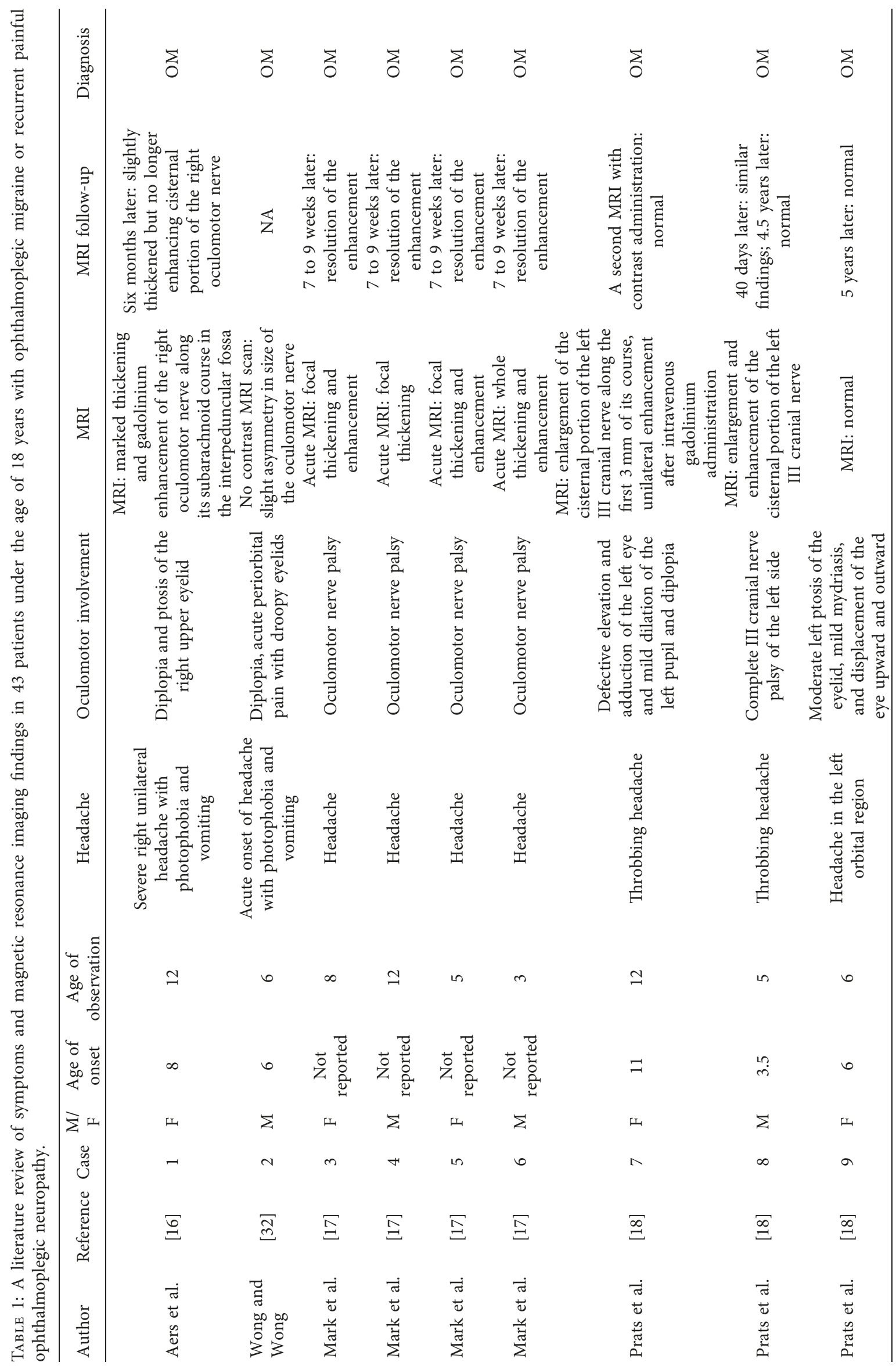




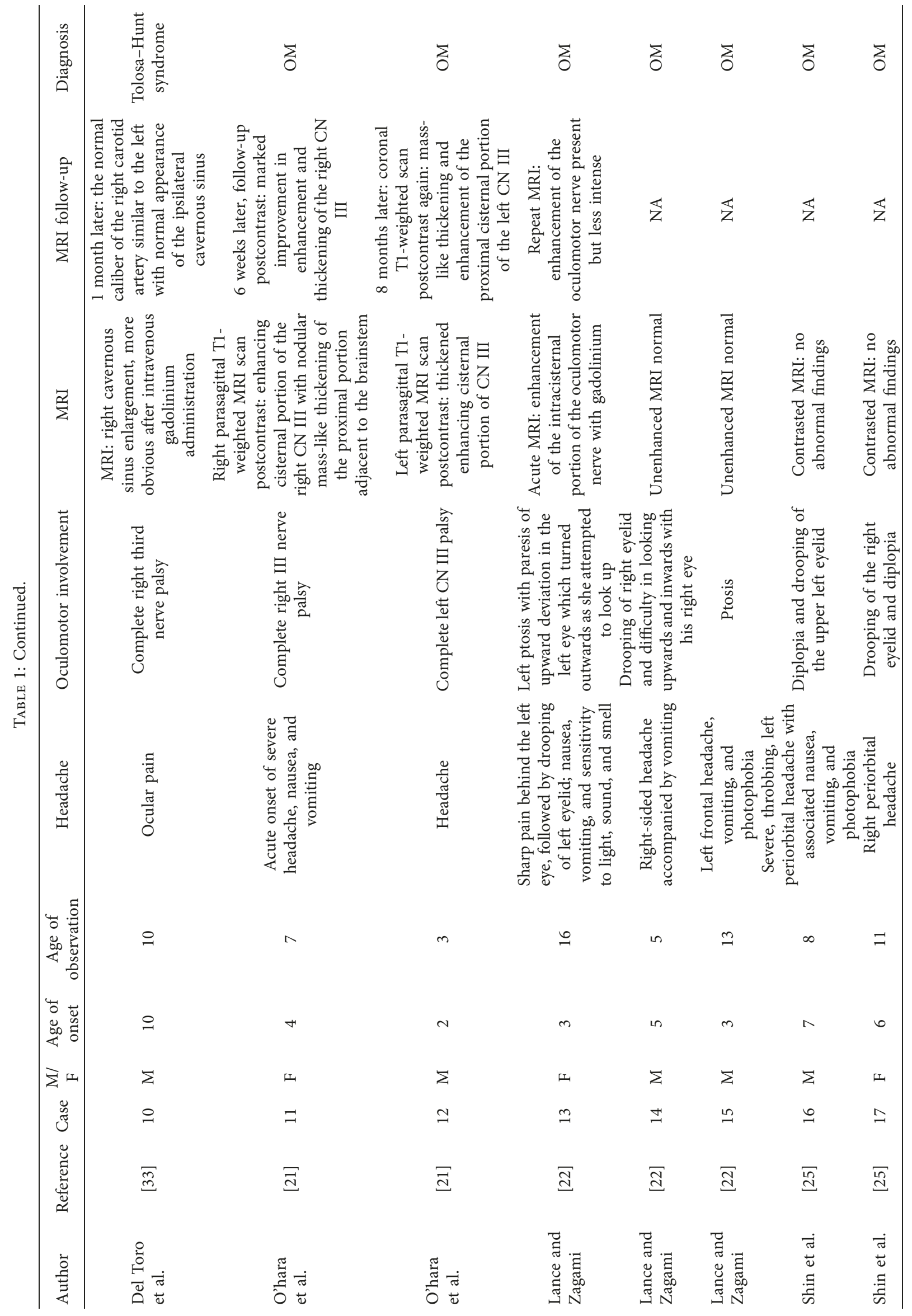




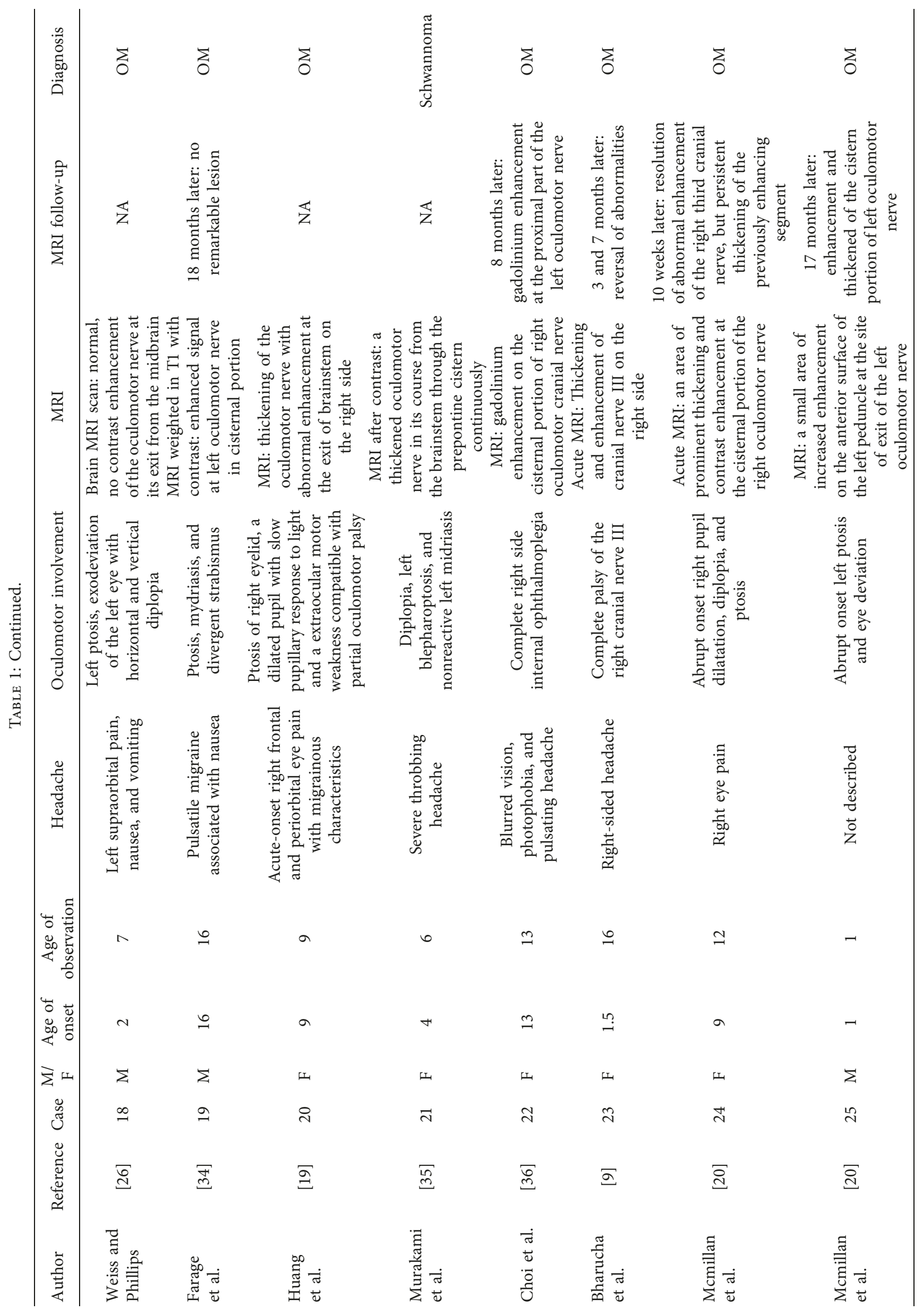




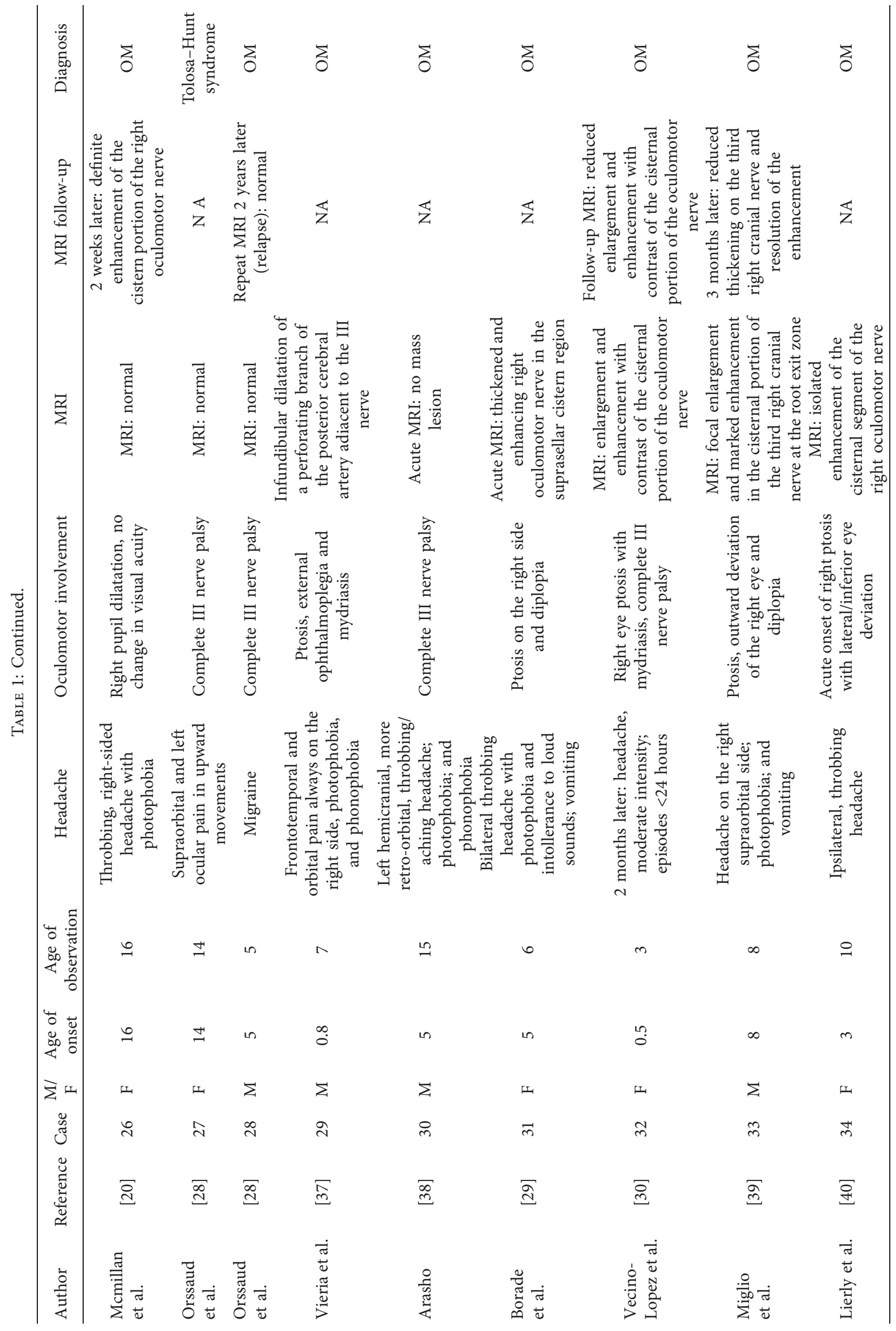




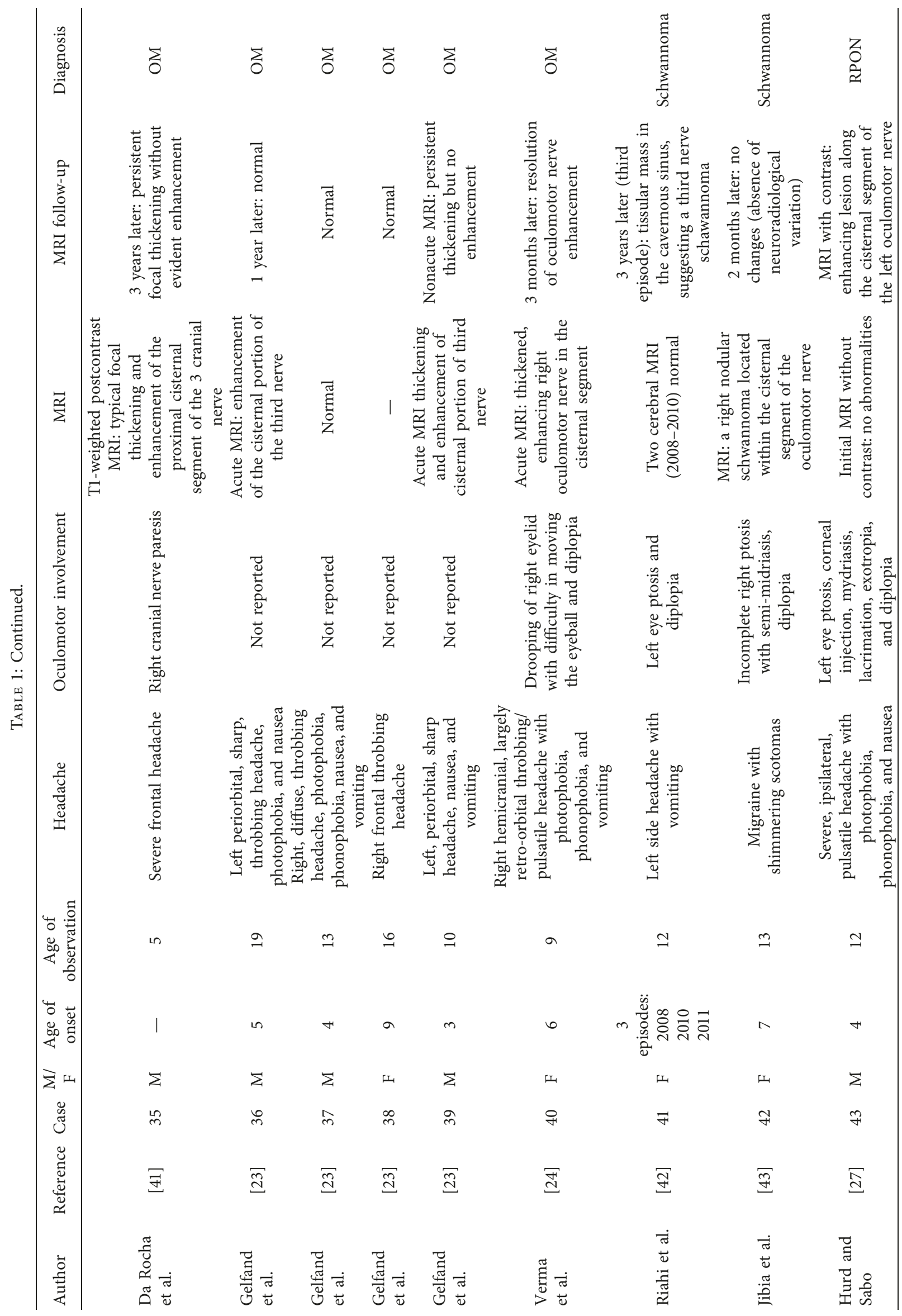


manifestation of the patient as a "primary" migraine, while the last brain MRI showed a focal enhancement of contrast, described as a schwannoma. The review of literature on MRI findings in child and adolescent patients affected by OM/ RPON (according to ICHD classifications over time) showed only three cases with isolated schwannoma of the oculomotor nerve associated with migraine and oculomotor nerve palsy after a long time history of III nerve paresis and/or migraine (Table 1). In 2005, Murakami et al. published the first histologically proved case of schwannoma in an 11year-old girl with a previous history of OM. The initial diagnosis of OM was corroborated by brain MRI. Five years later, the OM attacks became more frequent and not controlled by prophylaxis or acute episodes' drugs, and brain MRI with three-dimensional reconstruction shows a $5 \mathrm{~mm}$ nodular lesion highly suggestive of a neoplastic process involving the oculomotor nerve in its course from the brainstem through the prepontine cistern continuously. Histopathological finding after surgical treatment confirmed the diagnosis of schwannoma [35]. Riahi et al. in 2014 published the case of a 12-year-old girl who presented three episodes of left eye painful ophthalmoplegia during a period of 3 years. Two previous brain MRIs produced normal image scans, while the brain MRI made after the third episode showed a mass of tissue in the cavernous sinus suggesting a third nerve schwannoma [42]. Jibia et al. in 2015 published the case of a 13-year-old girl with a previous medical history of migraine since she was 6 years old. In coincidence of hospitalization because of an attack of disabling ophthalmic migraine, the brain MRI revealed a right nodular schwannoma located within the cisternal segment of the oculomotor nerve (patient was treated with analgesic and corticosteroid therapy with complete regression of symptoms three weeks later and a normal MRI follow-up) [43]. The most part of other cases included in our review, with OM/RPON diagnosis have short-term MRI follow-ups performed less than two years after the first evaluation that can show persistent thickening and enhancement $[16,17,20-24]$ or their negativization $[9,18,23]$. Therefore, it is important to consider the long-term evolution of RPON and its relationship with oculomotor nerve schwannoma. Two different speculative explanations of the eventual pathophysiological relationship between RPON and schwannoma have been proposed. The first one is related to the intermittent release of a chemical substance from the tumor, which results in the stimulation of the trigeminal nerve receptors leading to a migrainous headache. According to this hypothesis, the oculomotor nerve schwannoma mimics RPON, so the painful ophthalmoplegia may be considered as the initial manifestation of a tumor and may be too small to be appreciated in MRI scans $[35,44]$. A review of pediatric isolated oculomotor nerve schwannoma showed OM as one among the clinical signs of presentation of this tumor [11]. The alternative hypothesis is based on the idea that the underlying pathophysiology of RPON is an inflammatory cranial neuralgia and not migraine, so that repeated episodes of inflammation leading to demyelination and remyelination may be associated with a potential transformation into schwannoma from Schwann cells proliferation. According to this interpretation, isolated oculomotor schwannoma may be considered as a long-term complication of RPON.

\section{Conclusions}

In conclusion, both case reports we presented and the literature review of other pediatric cases of OM/RPON, suggest an existing relationship between RPON and schwannoma. Further longitudinal studies on a larger number of cases are needed to clarify whether in some patients an ocular motor nerve schwannoma may closely mimic RPON or, alternatively, if the RPON may be considered a risk factor to develop over time a schwannoma. Anyway, in both these situations, negative findings at MRI during an acute attack of RPON (without any thickening or gadolinium enhancement) do not rule out the possibility of a future evidence of the tumor, considering that schwannomas are generally slowly progressive. Serial brain MRIs during acute exacerbations and even between attacks are essential in the long-term follow-up of RPON, especially in the cases with childhood onset, in order to not delay the diagnosis of a possible oculomotor nerve schwannoma.

\section{Additional Points}

Clinical Implications. (i) Put the focus on the still open debate on arguments pro and contra a migrainous background of RPON; (ii) underlying the important role of serial brain MRIs in the long-term follow-up of RPON; (iii) further longitudinal studies are needed to clarify pathophysiological relationship between RPON and schwannoma.

\section{Consent}

The mother of the young patient gave informed written consent before taking part in the study.

\section{Conflicts of Interest}

The authors declare they have no conflicts of interest.

\section{References}

[1] IHS, "The International classification of headache disorders, 3rd edition," Cephalalgia, vol. 38, no. 1, pp. 1-211, 2018.

[2] R.-D. Treede, T. S. Jensen, J. N. Campbell et al., "Neuropathic pain: redefinition and a grading system for clinical and research purposes," Neurology, vol. 70, no. 18, pp. 1630-1635, 2008.

[3] K. J. Morgan and D. L. Anghelescu, "A review of adult and pediatric neuropathic pain assessment tools," The Clinical Journal of Pain, vol. 33, no. 9, pp. 844-852, 2017.

[4] B. W. Landry, P. R. Fischer, S. W. Driscoll et al., "Managing chronic pain in children and adolescents: a clinical review," PMßR, vol. 7, no. 11, pp. S295-S315, 2015.

[5] S. Evers, "Facial pain: overlapping syndromes," Cephalalgia, vol. 37, no. 7, pp. 705-713, 2017.

[6] IHS, "Classification and diagnostic criteria for headache disorsers, cranial neuralgias and facial pain," Cephalalgia, vol. 8, no. 7, pp. 1-96, 1988. 
[7] IHS, "ICHD-II classification: parts 1-3: primary, secondary and other," Cephalalgia, vol. 24, no. 1, pp. 23-136, 2004.

[8] S. V. Smith and N. M. Schuster, "Relapsing painful ophthalmoplegic neuropathy: no longer a "migraine," but still a headache," Current Pain and Headache Reports, vol. 22, no. 7, p. 50, 2018.

[9] D. X. Bharucha, T. B. Campbell, I. Valencia, H. H. Hardison, and S. V. Kothare, "MRI findings in pediatric ophthalmoplegic migraine: a case report and literature review," Pediatric Neurology, vol. 37, no. 1, pp. 59-63, 2007.

[10] L. Margari, A. R. Legrottaglie, F. Craig, M. G. Petruzzelli, U. Procoli, and F. Dicuonzo, "Ophthalmoplegic migraine: migraine or oculomotor neuropathy?," Cephalalgia, vol. 32, no. 16, pp. 1208-1215, 2012.

[11] S.-S. Yang, Z.-J. Li, X. Liu, Y. Li, S.-F. Li, and H.-D. Zhang, "Pediatric isolated oculomotor nerve schwannoma: a new case report and literature review," Pediatric Neurology, vol. 48, no. 4, pp. 321-324, 2013.

[12] Y.-H. Cho, K.-S. Sung, Y.-J. Song, D.-C. Kim, S. Choi, and K.-U. Kim, "Oculomotor nerve schwannoma: a case report," Brain Tumor Research and Treatment, vol. 2, no. 1, pp. 43-47, 2014.

[13] A. A. Norman, B. K. Farris, and R. M. Siatkowski, "Neuroma as a cause of oculomotor palsy in infancy and early childhood," Journal of American Association for Pediatric Ophthalmology and Strabismus, vol. 5, no. 1, pp. 9-12, 2001.

[14] I. H. Paheva and I. S. Ivanov, "Migraine variants: occurrence in pediatric neurology practice," Clinical Neurology and Neurosurgery, vol. 115, no. 9, pp. 1775-1783, 2013.

[15] IHS, "The international classification of headache disorders, 3rd edition (beta version)," Cephalalgia, vol. 33, no. 9, pp. 629-808, 2013.

[16] I. Aers, M. Van Zandijcke, I. Dehaene, and J. Casselman, "Magnetic resonance imaging in a case of migraine with ophthalmoplegia," European Journal of Neurology, vol. 4, no. 1, pp. 85-89, 1997.

[17] A. S. Mark, J Casselman, D. Brown et al., "Ophthalmoplegic migraine: reversible enhancement and thickening of the cisternal segment of the oculomotor nerve on contrast-enhanced MR images," American Journal of Neuroradiology, vol. 19, no. 10, pp. 1887-1891, 1998.

[18] J. M. Prats, B. Mateos, and C. Garaizar, "Resolution of MRI abnormalities of the oculomotor nerve in childhood ophthalmoplegic migraine," Cephalalgia, vol. 19, no. 7, pp. 655659, 1999.

[19] T.-H. Huang, W.-C. Hsu, J.-H. Yeh, H.-C. Chiu, and W.-H. Chen, "A case of ophthalmoplegic migraine mimicking ocular myasthenia gravis," European Neurology, vol. 53, no. 4, pp. 215-217, 2005.

[20] H. J. McMillan, D. L. Keene, P. Jacob, and P. Humphreys, "Ophthalmoplegic migraine: inflammatory neuropathy with secondary migraine?," Canadian Journal of Neurological Sciences/Journal Canadien des Sciences Neurologiques, vol. 34, no. 3, pp. 349-355, 2007.

[21] M. A. O'Hara, R. T. Anderson, and D. Brown, "Magnetic resonance imaging in ophthalmoplegic migraine of children," Journal of American Association for Pediatric Ophthalmology and Strabismus, vol. 5, no. 5, pp. 307-310, 2001.

[22] J. W. Lance and A. S. Zagami, "Ophthalmoplegic migraine: a recurrent demyelinating neuropathy?," Cephalalgia, vol. 21, no. 2, pp. 84-89, 2001.

[23] A. A. Gelfand, J. M. Gelfand, P. Prabakhar, and P. J. Goadsby, "Ophthalmoplegic "migraine" or recurrent ophthalmoplegic cranial neuropathy," Journal of Child Neurology, vol. 27, no. 6, pp. 759-766, 2012.

[24] A. Verma, A. Kumar, and V. Singh, "Ophthalmoplegic migraine in a child, an accelerated clinical and radiologic response to steroid therapy," Neurology Asia, vol. 17, no. 4, pp. 357-359, 2012.

[25] D.-J. Shin, J.-H. Kim, and S.-S. Kang, "Ophthalmoplegic migraine with reversible thalamic ischemia. Shown by brain SPECT," Headache: The Journal of Head and Face Pain, vol. 42, no. 2, pp. 132-135, 2002.

[26] A. H. Weiss and J. O. Phillips, "Ophthalmoplegic migraine," Pediatric Neurology, vol. 30, no. 1, pp. 64-66, 2004.

[27] A. Hurd and T. Sabo, "Episodic ophthalmoplegia and headache with cranial nerve III enhancement on MRI," Headache: The Journal of Head and Face Pain, vol. 58, no. 10, pp. 1685-1686, 2018.

[28] C. Orssaud, O. Roche, H. El Dirani, J. Allali, and J.-L. Dufie, "Les ophtalmoplégies douloureuses de l'enfant: place du syndrome de Tolosa-Hunt et de la migraine ophtalmoplégique," Archives de Pédiatrie, vol. 14, no. 8, pp. 996-999, 2007.

[29] A. Borade, A. S. Prabhu, S. Kumar, V. Prasad, and L. Rajam, "Magnetic resonance imaging findings in ophthalmoplegic migraine," Journal of Postgraduate Medicine, vol. 55, no. 2, pp. 137-138, 2009.

[30] R. Vecino Lopez, J. Casas Rivero, J. Alvarez-Linera, and S. Noval Martín, "Migraña oftalmopléjica: valor de la resonancia magnética," Anales de Pediatría.vol. 71, no. 1, pp. 72-75, 2009.

[31] D. I. Friedman, "The ophthalmoplegic migraines: a proposed classification," Cephalalgia, vol. 30, no. 6, pp. 646-647, 2010.

[32] V. Wong and W. C. Wong, "Enhancement of oculomotor nerve: a diagnostic criterion for ophthalmoplegic migraine?," Pediatric Neurology, vol. 17, no. 1, pp. 70-73, 1997.

[33] M. Del Toro, A. Macaya, E. Vazquez, and M. Roig, "Painful ophthalmoplegia with reversible carotid stenosis in a child," Pediatric Neurology, vol. 24, no. 4, pp. 317-319, 2001.

[34] L. Farage, M. A. Castro, T. A. Macedo, P. C. Borges, L. P. Souza, and L. O. Freitas, "Ophthalmoplegic migraine: MRI findings. Case report," Arquivos de Neuro-Psiquiatria, vol. 63, no. 1, pp. 173-175, 2005.

[35] T. Murakami, M. Funatsuka, M. Komine et al., "Oculomotor nerve schwannoma mimicking ophthalmoplegic migraine," Neuropediatrics, vol. 36, no. 6, pp. 395-398, 2005.

[36] J. Y. Choi, S. H. Jang, M. H. Park, B. J. Kim, and D. H. Lee, "Ophthalmoplegic migraine with alternating unilateral and bilateral internal ophthalmoplegia," Headache: The Journal of Head and Face Pain, vol. 47, no. 5, pp. 726-728, 2007.

[37] J. P. Vieira, J. Castro, L. B. Gomes, S. Jacinto, and A. Dias, "Ophthalmoplegic migraine and infundibular dilatation of a cerebral artery," Headache: The Journal of Head and Face Pain, vol. 48, no. 9, pp. 1372-1374, 2008.

[38] B. D. Arasho, "Ophthalmoplegic migraine in a 15-year-old Ethiopian: case report and literature review," Headache: The Journal of Head and Face Pain, vol. 10, no. 1, pp. 45-49, 2009.

[39] L. Miglio, P. Feraco, G. Tani, and P. Ambrosetto, "Computed tomography and magnetic resonance imaging findings in ophthalmoplegic migraine," Pediatric Neurology, vol. 42, no. 6, pp. 434-436, 2010.

[40] M. J. Lyerly, B. W. Peterson, A. K. Lara, and T. M. McGrath, "Ophthalmoplegic migraine," Headache: The Journal of Head and Face Pain, vol. 51, no. 7, pp. 1167-1168, 2011.

[41] A. J. Da Rocha, P. Breinis, and M. L. Monteiro, "Magnetic resonance appearance of recurrent ophthalmoplegic 
migraine," Arquivos de Neuro-Psiquiatria, vol. 70, no. 1, p. 77, 2012.

[42] A. Rihai, I. Ben Youssef-Turki, K. Walha et al., "Ophtalmoplégie douloureuse récidivante: migraine ophtalmoplégique ou schwannome du nerf oculomoteur ?," Pratique Neurologique-FMC, vol. 5, no. 3, pp. 205-208, 2014.

[43] A. Jibia, L. Chenin, M. Lefranc, and J. Peltier, "Oculomotor nerve schwannoma in a child: case report and literature review,” Neurochirurgie, vol. 61, no. 4, pp. 283-286, 2015.

[44] R. Kim, J. H. Kim, E. Kim et al., "Oculomotor nerve tumors masquerading as recurrent painful ophthalmoplegic neuropathy: report of two cases and review of the literature," Cephalalgia, vol. 35, no. 9, pp. 825-830, 2015. 


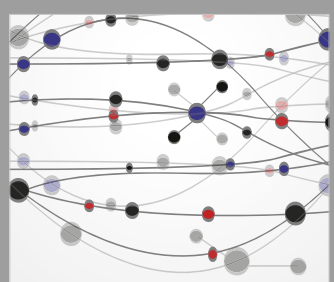

The Scientific World Journal
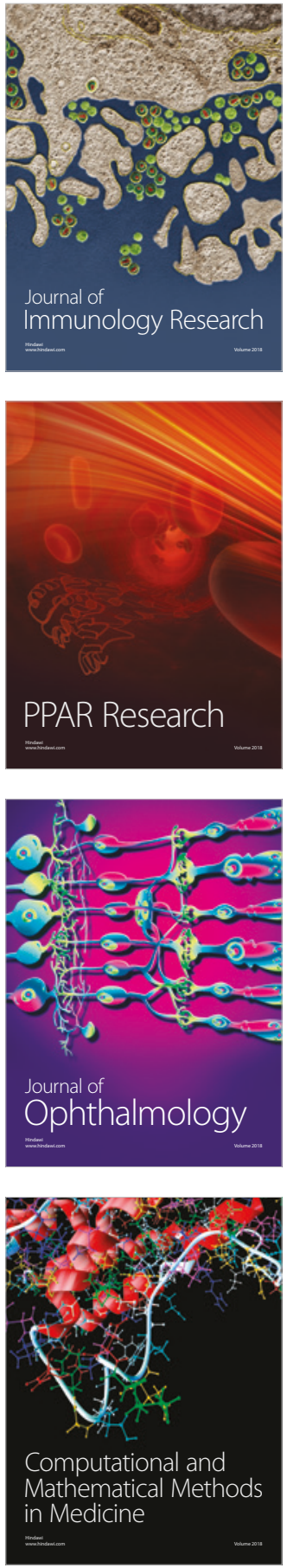

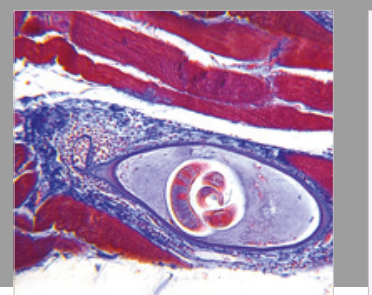

Gastroenterology Research and Practice

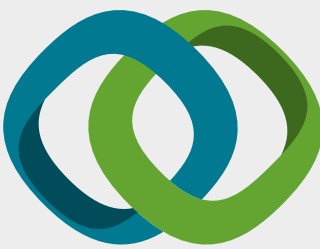

\section{Hindawi}

Submit your manuscripts at

www.hindawi.com
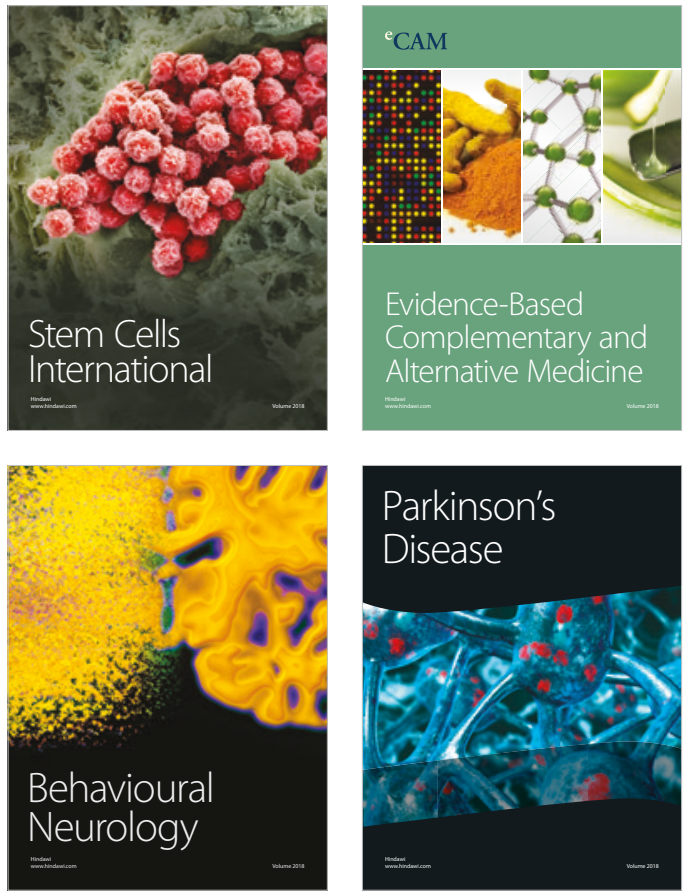

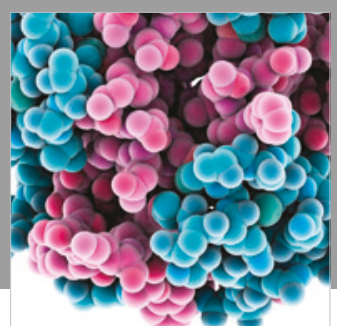

ournal of

Diabetes Research

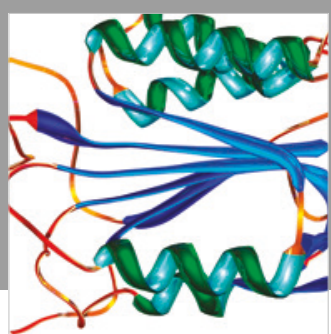

Disease Markers
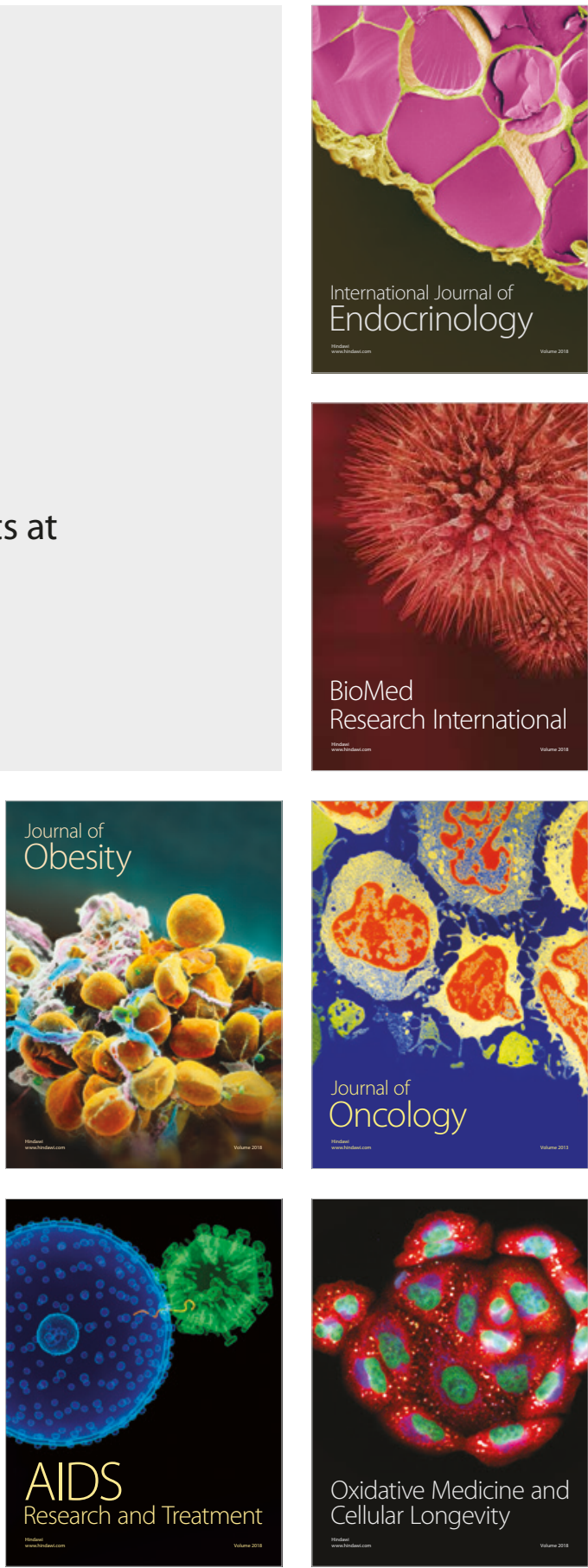